\title{
MODIFICATION OF THROTTLE, ENGINE STOP, AND DATA INPUT MECHANISM SYSTEM IN ELEVATION SYSTEM, AND ROTARY CANON TANK AMX 10 PAC 90 USING CAMERA SENSOR
}

\author{
Ayip Rivai Prabowo, Dueng Deriva, Endro Prasetijoadi, Sigit Bangun S. \\ Indonesian Naval Technology College, STTAL \\ Bumimoro-Morokrembangan, Surabaya 60187, Indonesia
}

\begin{abstract}
Along with technological developments in the industrial revolution era 4.0 military technology is required to be able to adjust to the development of human resources or defense equipment. Research that has been done previously is that the Throttle manually changed using Throttle with DC motor drive, there are some disadvantages caused by using a DC motor, among others, it is difficult to map the direction and speed of the motor so it is difficult to drive, the same as that used as an engine mover Stop that is by using a DC Type Motor while for the input system of rotary and elevation is still manually operated by the remote controller operator. From the debate that occurred the author will make modifications to the throttle system that uses a DC wiper motor in exchange for using an angle motor can be easily, for the engine Stop the same system that is initially using a DC wiper motor is replaced using a servo motor so that the mapping angle of 0 degrees to 90 degrees can be easily mapped, while for elevation and rotary canon by inputting data with the camera module using the camera sensor as for microcontroller data input
\end{abstract}

Keywords: Stop Engine, dc motor

\section{INTRODUCTION}

The MARINS Corps of the Navy or (Kormar) is one of the main commands of the Navy which in the organizational structure of the Navy, the Marine Corps is a main command whose task and position are parallel to other cities in the navy such as Koarmatim, Koarmabar, Kolinlamil, Kodiklatal, Seskoal and AAL. Kormar has the slogan Jalesu Bhumyamca Jayamahe which means in our sea and land Jaya. At present the strength of the Marine Corps is divided into 2 namely Marines (Pasmar 1) in Surabaya and (Pasmar 2) in Central Jakarta, Every Pasmar in charge of the Marine Infantry Brigade, Marine Assistance Regiment Combat Marines (Menbanpurmar), Marine Artillery Regiment (Menartmar) and Marine Cavalry Regiment (Menkavmar).

In carrying out their duties, functions and role as amphibious landing forces, the marine corps has a regiment unit of Cavalry Regiment units namely amphibious tank battalions which are an important part of amphibious landing forces. The marine amphibious tank battalion carries out the training mission and the use of its power in the context of the projection of landing forces from the sea on land in amphibious operations. With the chess motto the magic power of the amphibious tank battalion has 4 strengths namely firepower, shock power, buoyancy and armored power, the main components of amphibious tank battalions are amphibious tanks, which are one of the elements in amphibious operations as the first landing wave to seize the coast which will be the foothold in the amphibious invasion. At present the battalion of marine amphibious tanks is reinforced by combat vehicles including PT 76 Tank, PT 76 (M) Tank, AMX 10 PAC 90, BTR 80 A.

Based on surveys in the Karangpilang Marine tank battalion. In amphibious operations and training one type of ranpur used is AMX 10 PAC 90, which is equipped with a $90 \mathrm{~mm}$ caliber CS Super (F4) gun, $7.62 \mathrm{~mm}$ caliber AA machine gun, with 3 ranpur crew and 4 bodyguards. But in an amphibious operation and training, accidents often 
occur in these amphibious tanks which can cause personnel losses. There are several technical and non-technical factors that can cause accidents when the tank is used, among others. With the engine condition in front of the right, the $A M X 10$ tank encountered obstacles at the time speeding in water or sea, limited visibility while driving, operators often experience fatigue when operating which can reduce the ability and concentration of the operator, even when driving on this land Ranpur easily rolled, so prone to loss of personnel.

This must be resolved immediately, one way to minimize personnel losses by seeking AMX 10 PAC 90 amphibious tanks so that they can be controlled automatically. then it needs to be modified in several controlling mechanisms including: throttle system, Engine Stop, elevation data input and rotary canon tank AMX 10 PAC 90 with a device that can replace the function and role of the operator so that the opportunity for personnel losses can be minimized.

Along with technological developments in the 4.0 industrial revolution era, military technology is expected to adjust to developments, both human resources and defense equipment technology. Under these conditions, research and development of defense equipment technology has been carried out, one of which is by modifying the AMX 10 PAC 90 Tank battle vehicle made in France.

Initial conditions required at least 5 personnel of Marines, with these modifications expected to be manned 1 to 2 as operator controller and assistant operator. Previously, modifications have been made to the Throttle mechanism system, engine stop and rotary elevation system on the AMX 10 PAC Tank. (Deni, 2018). In this thesis the author will modify, including modifying the mechanism of the Throttle, Engine Stop, and rotary systems and elevation using the camera sensor as a microcontroller data input.
Previous research has been done by manually changing the Thorttle using the Thorttle with DC wiper motor drive in Figure 1., some disadvantages that can be caused by only using a DC wiper motor, among others, it is difficult to map the direction and speed of the motor so that it is more difficult in programming controller, as well as to be applied as an Engine Stop mover, namely by using a DC Type Wiper Motor untuk input sistem rotary dan elevasi masih secara manual dioperasikan oleh operator pemegang remot kontroler.

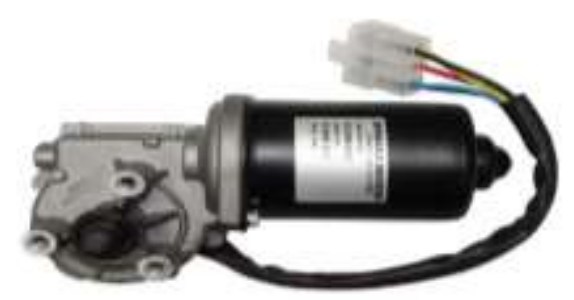

Fig.1 DC Wiper motor (Source: http://www.partdeal.com)

Hope by modifying the system Throttle, Engine Stop, and rotary system mechanism as well as elevation by using the camera sensor as a microcontroller data input can overcome the problems that have so far occurred in the AMX 10 PAC 90 Tank so that in operation no more obstacles occur in the throttle system which was initially difficult in mapping acceleration angle does not happen again, the Engine Stop is no longer a problem in the process of closing the air valve from 0 degrees to 90 degrees and the elevation system and rotary canon can be facilitated in taking data input using the camera module. The plan of the solution to the problem that occurred the author will make modifications to the throttle system which initially uses a DC wiper motor instead of using a servo motor so that the angle mapping can be easily, for the Engine Stop system is the same, initially using a DC wiper motor instead of using a servo motor so that the mapping angles from 0 degrees to 90 degrees can be easily mapped, while 
for elevation and rotary canon by inputting data with a camera module using the camera sensor as a microcontroller data input

\subsection{Formulation of the problem}

In this study the problem can be formulated as follows:

a. How to perfect the Thorttle mechanism, Engine Stop by using a servo motor so that it is achieved as expected.

b. How to perfect the rotary system drive input and elevation of the dome and canon Tank AMX 10 PAC 90 which was originally done manually refined with a camera sensor input.

\subsection{Research purposes}

The objectives to be achieved in implementing improvements to the two systems are:

a. Provide solutions to problems that often arise by using DC motors on the Thortle and Engine Stop.

b. Helps the controller maneuver more easily to get input distance target data so that the accuracy of the target is right.

\subsection{Scope of problem}

This research is a refinement of the previous design and research so that a number of things become the limitation of the problem:

a. Not discussing about the Microcontroller Program Code.

b. Changes in rotary angle and elevation in accordance with the program that has been assumed so that for accuracy in accordance with ranpur spectra it is necessary to hold further data collection.

c. Joints and bearings are considered safe.

\subsection{Benefits of Research}

The benefits of this research are

a. Adding technological knowledge in the field of Throttle system mechanism b. Can be a motivation for other students in supporting the achievement of the STTAL motto as Road To Research University.

c. Can assist the crew to carry out combat operations in the Navy environment.

d. Can be useful for YonTank who need to organize a combat training activity.

e. Reducing the occurrence of loss of personnel when participating in battlefield activities if Prior Research

\section{MATERIAL AND METHODS}

\subsection{In previous studies the ThroTtle system.}

In the AMX 10 PAC 90 Tank has been modified using mechanical control with a Wiper motor actuator which is a DC motor with a Gearbox mechanism so that it produces a large enough torque, the same as that used in the engine stop or stop karburant in the tank. AMX 10 PAC 90 while the target ploting system which involves the role of dome rotation and canon elevation Tanks still use cameras

Analog without proximity sensor / Range Finder and Rotari correction and shooting elevation are not synchronized with the camera.

\subsubsection{Throttle Drive System}

The Throttle drive system which originally used a pedal operated by the AMX Tank driver, was modified in previous studies by using an active electro mechanical after the microcontroller provides an input signal to the DC motor driver which will then drive the DC motor on the Throttle.

\subsubsection{Tank Dome Elevation and Rotary Input Systems}

a. Parts of control and function:

1) The elevation lever functions as a canon barrel driver if the driving lever is rotated then the canon barrel will move from coordinates $00-450$

2) The lock functions as a lock which after the canon barrel has finished operating 
with the target it will be locked so that there will be no change in the canon barrel.

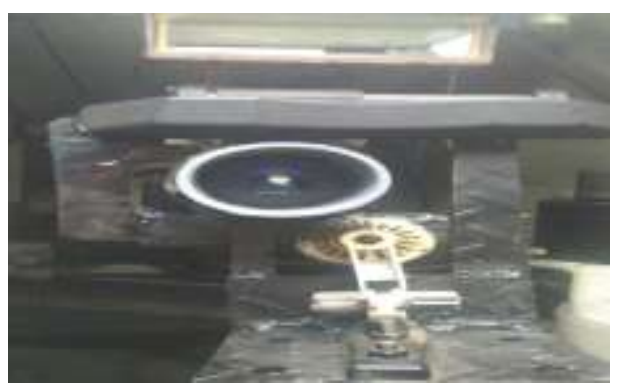

Fig.2 AMX Tank Telescope

(Source: Self-processed)

b. How the operation works on the elevation by pressing the elevation (+) to raise the angle of the barrel so that it has an angle $>0$.

c. Operating Procedure on the dome rotation system by pressing the rotation (+) button on the remote for angles $>0^{\circ}$ and rotation (-) for angles $<0^{\circ}$

\subsection{Theoretical basis}

\subsubsection{Scatter Motor}

A DC drive motor is a motor that requires a direct current voltage supply in the field coil to convert into mechanical motion. The field coil on a DC motor is called a Stator (non-rotating part). Direct current motors, as the name suggests, use direct current that is not direct / direct-unidirectional. DC motors have 3 main parts or components to be able to rotate as follows.

a. The main part or component of a DC motor. Polar terrain Two-pole motor polar terrain north to south.

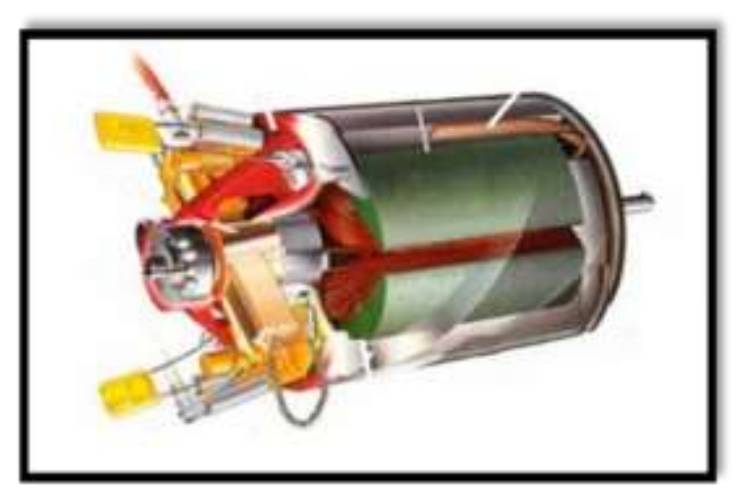

Fig.3 DC Motor

(Source: Amazon.com)

\section{b. Advantages in DC motors}

The advantage in a DC motor is as a speed controller, which does not affect the quality of the power supply.

c. Electromagnetic force (E)

Where:

$E=$ Electromagnetic force on the dynamo terminal

$\varnothing=$ Field flux which is directly proportional to the field current

$N=$ Speed in RPM (revolutions per minute)

$\mathrm{T}=$ Electromagnetic torque

$\mathrm{la}=$ Current dynamo

$\mathrm{K}=$ Equation constant

d. Torque

Torque (torque) in general, torque is the force used to move something with a certain distance and direction. (Serway, 2003).

Then the torque formula can be derived as: $\mathrm{T}=\mathrm{F} . \mathrm{r}$

Where :

$\mathrm{T}=$ Torque Newton meter (N.m);

$\mathrm{F}=$ newton driving force $(\mathrm{N})$

$r=$ radius, meter $(m)$

While the relationship of torque to power (power) on a motor is:

$P=\omega \cdot T$

Where :

$\omega=$ angular velocity, radians $/ \sec (\operatorname{Rad} / \mathrm{s})$

$\mathrm{P}=$ Power or power, Watt $(\mathrm{W})$

For electric motors, the formula for angular velocity is:

$\omega=2 \pi . n / 60$

Where :

$\mathrm{n}=$ Motor rotation speed $(\mathrm{rpm})$

From the three equations above it can be seen that the power needed by the motor is proportional to the amount of torque produced at a certain speed. 


\subsubsection{Servo Motor}

Servo motor is a DC motor with a closed feedback system where the position of the rotor will be informed back to the control circuit that is in the servo motor. This motor consists of a DC motor, a series of gears, potentiometers, and a control circuit. Potentiometer serves to determine the angle limit of the servo rotation. While the angle of the axis of the servo motor is set based on the width of the pulse sent through the signal foot of the servo motor cable.

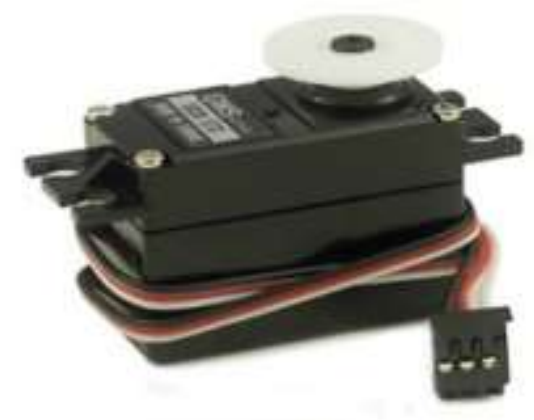

Fig.4 Servo Motor

(Source: Jsumo.com)

\subsubsection{Carbon steel plate}

Carbon steel is a metal material formed from the main element $\mathrm{Fe}$ and the second element that influences its properties is carbon, while the other elements are influential according to their achievements. The use of carbon mix is needed in the use of a tool. This low carbon steel has properties that are easily machined or forged. This low carbon steel contains carbon between $0.025 \%$ $0.25 \%$ C. every one ton of low carbon steel contains $10-30 \mathrm{~kg}$ of carbon. Carbon steel is in trade made in steel plates, strip steel and steel bars or profiles. (Rusmandi, 2006).

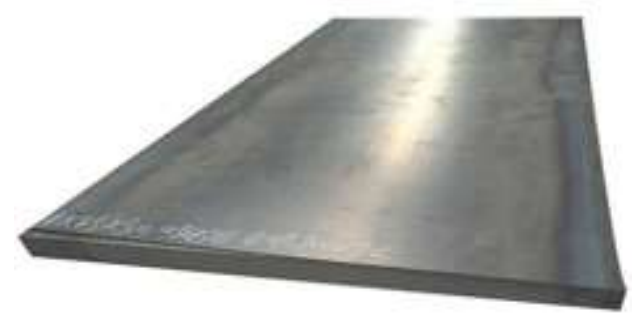

Fig.4 Figure Carbon Plate
(Source: indonesia hotwork.com)

\subsubsection{Arduino}

Arduino is an open-source single-board micro controller, derived from the Wiring platform, designed to facilitate the use of electronics in various fields. The hardware has the Atmel AVR processor and the software has its own programming language.

Arduino Uno is the most widely used. Especially for beginners it is recommended to use Arduino Uno The latest version is Arduino Uno R3 (Revised 3), using ATMEGA328 as its microcontroller, has 14 digital pin I / O and 6 pin analog inputs. For programming, just use a type $A$ to To type B USB connection. Same as used on a USB printer.

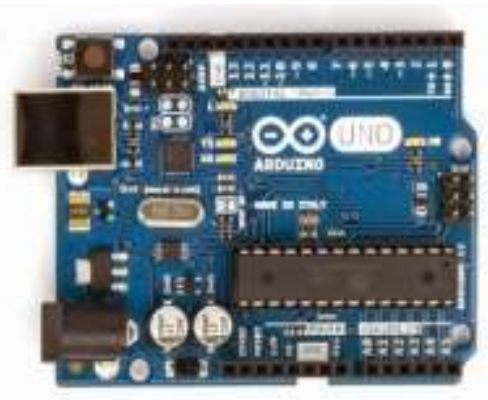

Fig.5 Arduino Uno

\subsubsection{Relay}

Relay is a device that works based on electromagnetism to move a number of arranged contactors or an electronic switch that can be controlled from other electronic circuits by utilizing electricity as its energy source. Contactors will be closed (lit) or open (off) due to the magnetic induction effect produced by the coil (inductor) when electrified. Unlike the switch, contactor movement (on or off) is done manually without the need for electric current. The simplest relay is an electromechanical relay that provides mechanical movement when getting electrical energy.

Simply stated this electromechanical relay is defined as a device that uses electromagnetic forces to close or open switch contacts. Switches 
that are driven mechanically by electric power or energy. As an electronic component, relays have an important role in a system of electronic circuits and electrical circuits to drive a device that requires large currents without connecting directly to a controlling device that has a small current. Thus the relay can function as a safety.

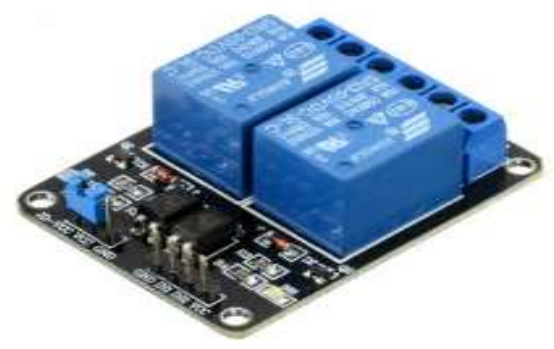

Fig.6 Relay

(Source: Daycar.com)

The relay consists of 3 main parts, namely:

a. Common, is the part that is connected with Normally Close (under normal circumstances).

b. Coil (coil), is the main component of the relay that is used to create a magnetic field.

c. Contact, which consists of Normally Close and Normally Open.

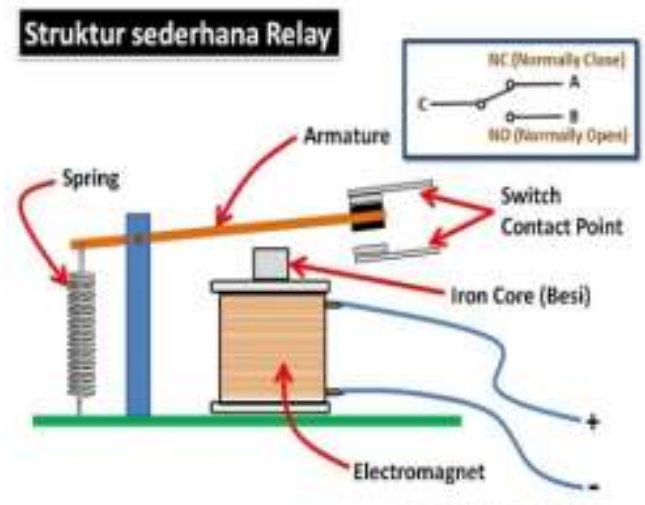

Fig.7 Simple relay structure

(Source: https: //teknikelektronika.com)

Based on the picture above, an iron (Iron Core) is wrapped around a coil coil that serves to control the iron. If the coil is given an electric current, an electromagnetic force will arise which then pulls the Armature to move from the previous position (NC) to a new position (NO) so that it becomes a switch that can deliver electric current in its new position (NO). (Sanitary, 2009). Some Relay functions that have been commonly applied into Electronic equipment include:

a. Relay is used to run the Logic Function (Logic Function)

b. Relay is used to provide a Time Delay Function.

C. Relay is used to control high-voltage circuits with the help of low-voltage signals.

d. There is also a Relay that serves to protect the Motor or other components from excess voltage or short circuit (Short)

\subsubsection{Motor Diver}

The motor driver is a part that functions to drive the DC Motor where the change in the direction of the DC motor depends on the value of the input voltage at the input of the driver itself.

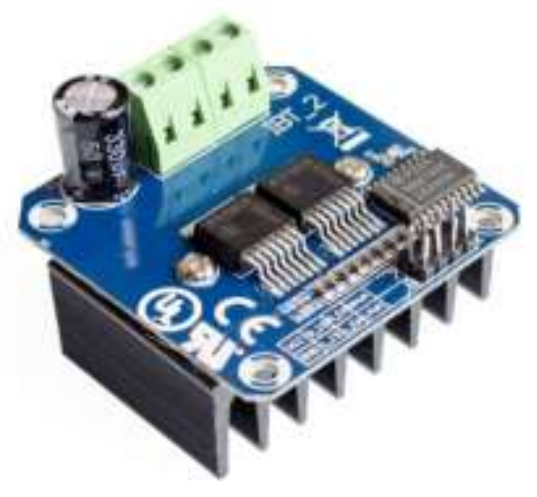

Fig.8 Motor Driver (Source: Daycar.com)

Rotating speed of the motor. Types of motor drivers include:

\section{a. Driver Control Voltage}

With the voltage control motor driver using the voltage level directly to regulate the speed of the motor rotation.

\section{b. PWM driver}

With PWM control we can regulate the speed of the motor by giving pulses with a fixed frequency to the motor, while what is used to regulate the speed is the duty cycle of the given pulse.

c. H-Bridge Driver 
The type $\mathrm{H}$ driver is used to control the rotation of the motor which can be adjusted in the direction of rotation of the CW (clockwise) and CCW (counterclockwise). This driver basically uses 4 transistors for switching (switch) of the motor rotation and alternately to reverse the polarity of the motor.

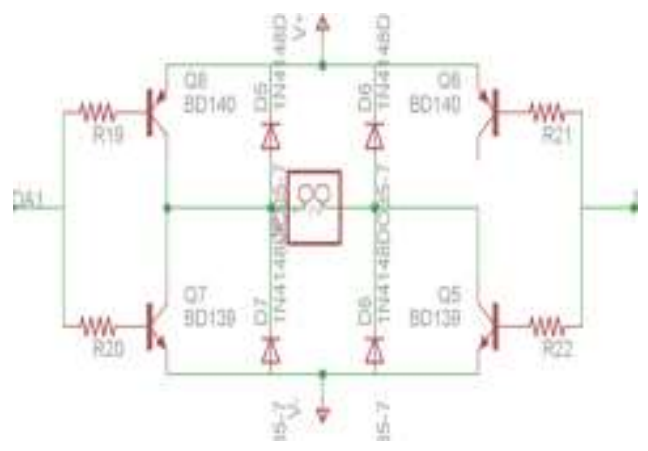

Fig.9 H-Brigde motor driver type (Source: Daycar Drawing.com)

\subsubsection{Buck Converter}

Buck Converter is a series of electronics that serves as a $D C$ to $D C$ voltage reducer by switching methods.

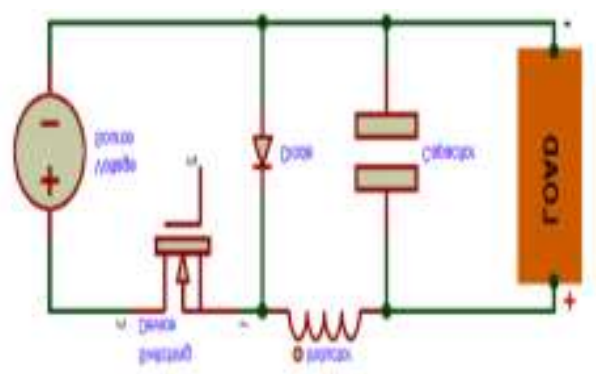

Fig.10 DC Buck Converter Circuit (Source: https://www.nyebarilmu.com)

The function of the constituent components above is that the MOSFET is used as a current counter according to the duty cycle setting so that the DC Chopper output matches the value that the Drive Circuit setting is used to control the MOSFET, so the timing for the MOSFET working can be controlled when it should be on or off. Buck type buckper can be considered when:

a. When the Swith is Closed (switch closed) the diode works recerved / block so that the input supply flows to the inductor as well as the load. b. When the Swith Opened (switch is open) the diode works forward / unblock so that the energy stored in the inductor can flow to the load.

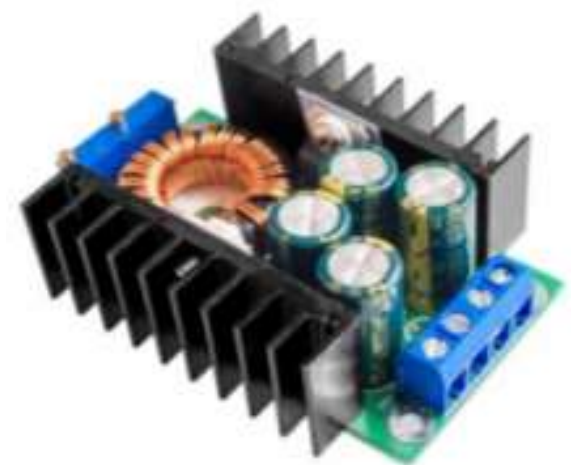

Fig.11 Buck Converter

(Source: https://hacktronics.co.in)

\subsection{Research design}

At this stage the research design is carried out with several stages that must be carried out by searching for data from sources such as literature review and field survey. From the literature review and survey in the field we can get the results of the data. Which can then be calculated and determine the components. From the results of the calculation and selection of components, the next stage is the assembly or incorporation of tools that have been designed or made, followed by testing the tools. Data during carrying out the test results are recorded to be used as evaluation material followed by making the preparation of results. After all the stages have been passed, a report can be prepared as outlined in the final project book.

\subsection{Research procedure}

Research procedures before starting to carry out research in advance carried out data collection on objeck to be refined by the place of data collection carried out at STTAL on AMX 10 PAC 90 Tank objects that have been modified, the data taken is not a raw data where ranpur used as reference is ranpur previous research results.

\subsubsection{Time and Place}


The time of research since the data collection, data processing, execution, testing and evaluation are carried out. for 6 months starting from June until December 2019, the place for data collection and design is in the STTAL environment.

\subsubsection{Research Tools and Materials}

In helping data retrieval to carry out research needed some supporting equipment, among others.

\subsubsection{Research Design}

Before starting to implement the modification and design of the mechanism, the collection of information needed first through the literature, text books, and from other sources, after the data collected and then carried out the determination of the topic of discussion raised in the writing of the Final Project. In this final project the topic raised is about how to modify the Throttle mechanism, Target Stop Ploting Engine by using the camera sensor as input data, then the camera reading data is processed in an Arduino microcontroller then the microcontroller gives instructions to the relay which will be forwarded to the motor elevation and rotation

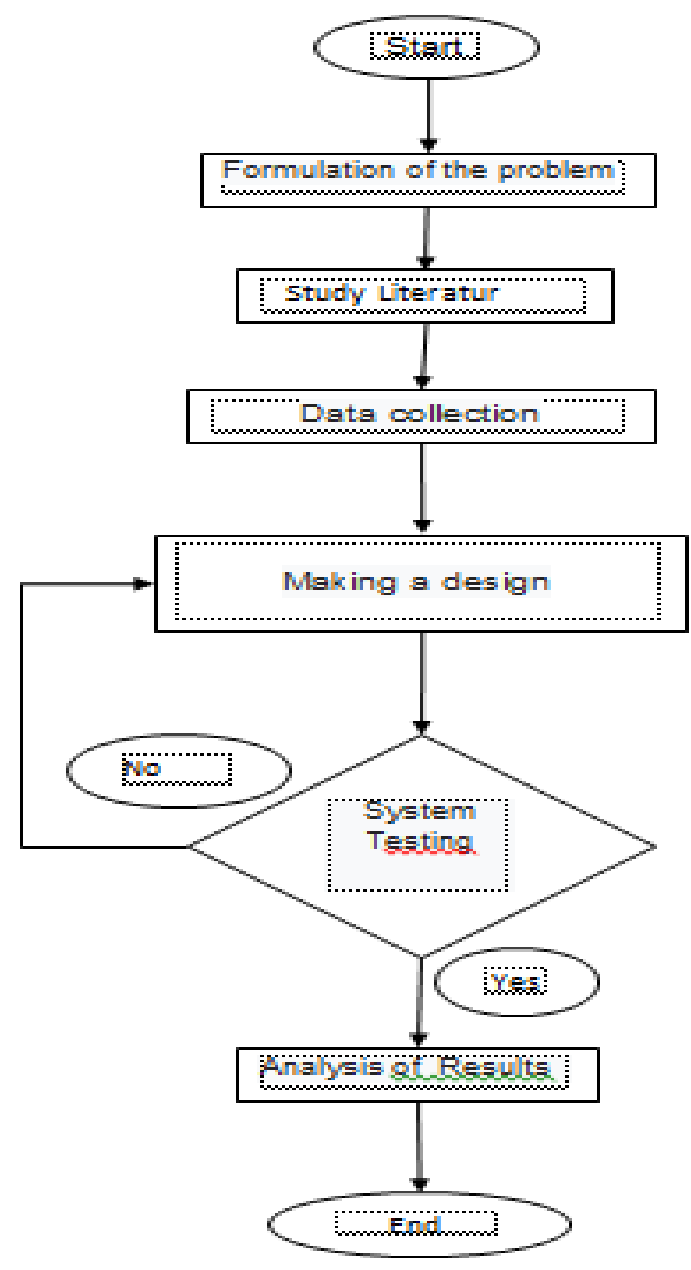

Fig.12 Research Flowchart (Source: Self-processed)

\subsection{Data collection}

Data collection method is a way of why and how the data that has been needed can be collected so that the final results of research can be able to present valid and reliable information. There are several stages for data collection in this study, including the following:

a. Reference data collection for DC motor access and input output components which are obtained from the internet and books or journals.

b. Collecting data obtained from the field used for testing tools when completed later. elements in the field such as materials for making a design and driving control.

\subsection{Data processing}

The technique in data processing used for this final project research is by measuring the tools on the steering wheel, designing the system, 
calculating the shape, the properties that exist in the mechanical material and calculating how much the speed of a DC motor and calculating the losses that occur in the wiper motor to move the load existing in the lever timing system at that elevation. When collecting data from the AMX 10 PAC 90 ranpur tank conducted at the STTAL Campus, when collecting data there was a problem with the problem that the conditions on the holder at the timing of the lever are very narrow space so an experiment must be carried out the exact place holder for the motor drive holder.

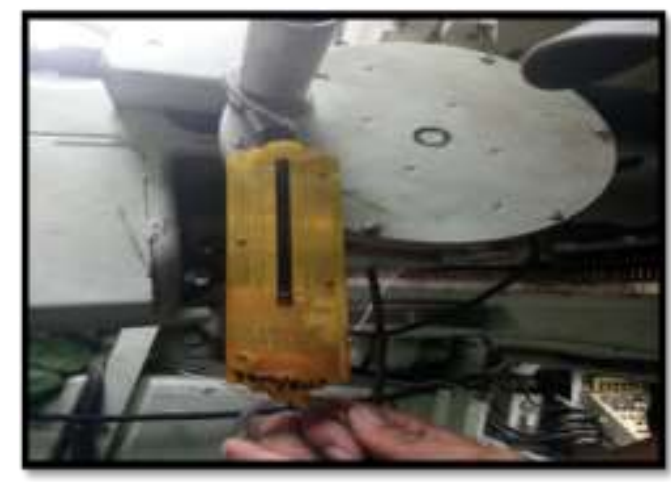

Fig.13 Measurement of Elevation Levers with Spring Balance

(Source: Processed by yourself)

The process of taking and collecting data on these elevation steering lever tools is done by conducting an experiment up to the number of times the results obtained can be made as a comparison of the measurement benchmarks of the first data collection, up to the second data and subsequently, the tools used are like the following picture:

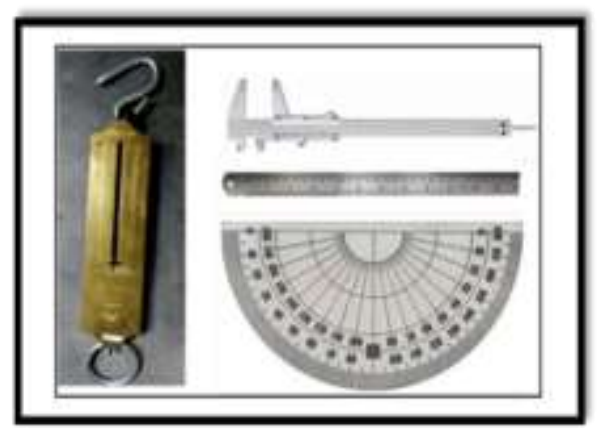

Fig.14 Measuring Instruments (Source: Kitchen Engineering)

\section{DISCUSSION AND RESULTS}

The system modification design in this chapter includes the combination of hardware design of the mechanical system and software design that is integrated using a microcontroller system. The combination is a combination of an open network control system and a closed network control system. Modification of the system is done both on the camera sensor, which is then the data the reading results are processed by Arduino to be used to give commands to each DC motor actuator.

\subsection{Tool Schema}

The electronic circuit scheme is made with the aim to facilitate the design of the components of the microcontroller and its supporting devices so that it can drive a series of DC motors that have been installed. The series of schemes are arranged according to each mechanism of action. In Figure 15 , the microcontroller circuit scheme, showing the parts of the electrical system design and the control control system of the modified device, from the picture that has been made is expected to help in the system design process.

\subsection{Full DC Motor Control Design}

Control elevation and rotary control on the cannon barrel using a DC motor, with the results of data processing that is read by the camera sensor and range finder and added a limit swich (as a limiter to the motion of the dc motor), relay (normaly open and normaly close to the voltage), converter (lowering the voltage), and Arduino Mega 2560 (programming algorithm), when as shown in Figure 15 , a clear picture of the DC Motor actuator control system is clearly illustrated. The actuator drive is working on 24 Volt voltage, which is obtained from 212 Volt batteries arranged in series. Whereas the Arduino control voltage gets a working voltage of 5 volts obtained from the Buck Converter stepdown circuit which serves to reduce the voltage of 24 volts to 5 volts. Then Arduino processes the sensor 
readout data to then give commands through relays and motor drivers that are set according to the control pin, the active Relay and motor driver are ordered by Arduino to pass a 24 Volt voltage on the DC motor, so that DCV is active and the motor moves according to the command.

a. Throttle control

Throtle drive mechanism which initially used a 24V DC wiper motor was modified by adding intermittent mechanisms and using a Servo Motor actuator, so that it is more precise, when mapping acceleration as expected, namely the incremental incremental acceleration from the stationary position to the acceleration then no obstacles occur. Throttle can map the angle of each servo adding acceleration the servo motor moves from 0 degrees to 20 degrees. each throttle increases the acceleration of the servo motor up 20 degrees and so on. if to reduce acceleration on the throttle simply by pressing the neutral gas button then the microcontroller automatically instructs the servo motor to return to the position of 0 degrees, so that the throttle is in a stationary state. The following is the throttle control system:

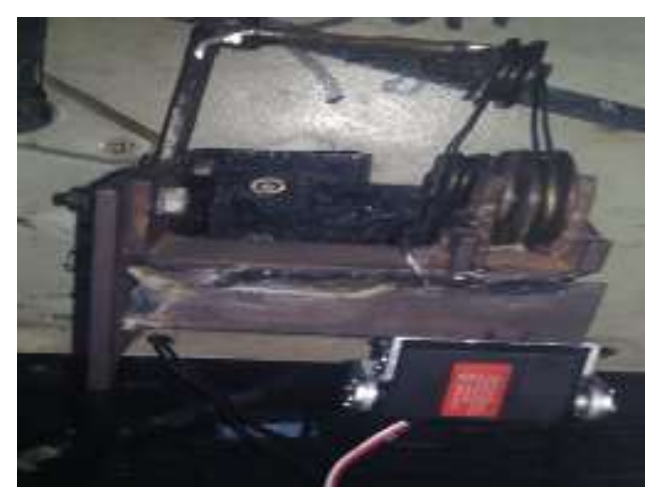

Fig.15 Throttle Mechanism (Source: Self-processed Results)

\section{b. Engine Stop Control}

Engine Stop driving mechanism initially using a wiper motor there is a motor difficulty in mapping the angle of 0 degrees and 90 degrees, then modified by replacing the wiper motor with a servo motor so that mapping of 0 degrees open air valves and 90 degrees closed valves does not occur difficulties in mapping and fast motor responsibility. The motor actuator control for the Engine Stop is carried out by Arduino connected from pins A10 and $A 11$ then passed through pins IN1 and IN2 on the motor module motor driver L298, When the motor driver module receives a signal at pins IN1 and IN2, the motor operating voltage of 24 VDC is distributed to move the motor.

c. Full mechanism of elevation dc motor

Discussing the motor elevation mechanism, this motor serves as the movement of the barrel gun up and down. The input of the camera sensor in the form of pixels is translated by the Arduino microcontroller where the microcontroller will use a mathematical algorithm to compare the dimensions of real objects and pixels detected by the next camera as a result of data processing allocated ports on the Arduino microcontroller connected from pins $A 15$ and $A 14$ then forwarded towards the $C$ pin 2 relay circuit, then a 24 Volt working voltage is directed to the DC Motor to drive the pulleys on the cannon barrel.

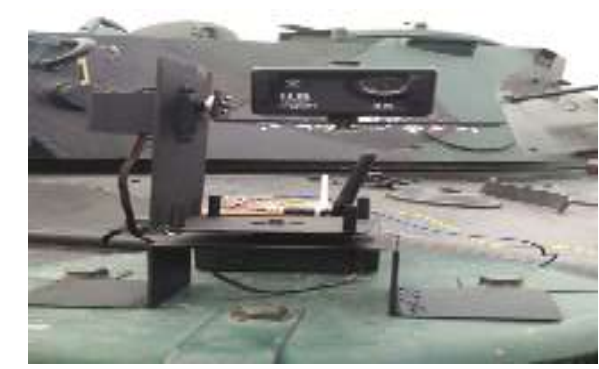

Fig.16 Full mechanism of elevation dc motor (Source: Self-processed Results)

Following also with the rotary motor mechanism, the input data from the camera reading results are processed in an Arduino microcontroller by using a motor on the camera sensor as an angle reference, the microcontroller will give commands to this motor that functions as a rotating cannon barrel motion. Arduino commands are connected from pins $A 13$ and $A 12$ and then forwarded to the relay circuit $C$ pin 2 , then a working voltage of 24 volts is directed to the DC motor to drive pulleys on the cannon barrel. This tool works as a target finder 
using visual aids namely with the camera as, the target search is done by searching for the target object, after the target is locked by pressing the button on the remote control then the microcontroller sends a signal to the motor diver and then continues the signal to move the motor elevation and the motor rotation of the tank by following the angle of the target search results according to the servo motor. The following programming language in Arduino as a follow-up command to drive the servo motor on the elevation and rotary systems on the Amx 10 PAC 90 canon tank is as follows:

Data Sheet for the Elevation Program:

void elevator ()

\{if (read_elevasi_up $==" 1 "$ )

\{digitalWrite (io_elev1, HIGH);

[//Serial.print("koplingnyala "); \}

if (read_elevasi_up $==$ "0")

\{digitalWrite (io_elev1, LOW);

In the data above is a language for programming the Elevation system on the canon tank vault for servo motors, the data contained if language (read_elevasi_up == "1") (io_elev1, $\mathrm{HIGH}$ ); This means that the servo motor gets an order from Arduino to move up because it has a current (high). While for the elevation up "0" on the motor moves down again at the initial position or 0 degrees.

$$
\begin{aligned}
& \text { if (read_elevasi_down == "1") } \\
& \text { \{digitalWrite (io_elev2, HIGH); } \\
& \text { //Serial.print("koplingnyala "); } \\
& \text { if (read_elevasi_down == "0") \{ } \\
& \text { digitalWrite (io_elev2, LOW); }
\end{aligned}
$$

As for the elevation position, the program language goes down as above, namely in the program language if (read_elevasi_down == "1") digitalWrite (io_elev2) ( $\mathrm{HIGH}$ ); This is a language for programming elevation systems on the canon tank vault for servo motors, in the data there is an if language (read_elevasi_down == "1") \{(io_elev2,
HIGH); means the servo motor gets an order from Arduino to move down to the bottom because it gets current (high). While for the elevation down "0" on the motor moves back down to the initial position or 0 degrees because it gets current (low). Data sheet canon tank rotary program

$$
\begin{aligned}
& \text { void rot () } \\
& \text { \{if (read_rotari_left =1 ") } \\
& \text { \{digitalWrite (io_rot1, HIGH); } \\
& \text { //Serial.print("koplingnyala "); } \\
& \text { if (read_rotari_left == "0") \{ } \\
& \text { digitalWrite (io_rot1, LOW); }
\end{aligned}
$$

Based on the programming language data above is a program that is in Arduino \{if (read_rotari_kiri $==" 1 ")$ \{digitalWrite (io_rot1, $\mathrm{HIGH}$ ); to order the servo motor to move to the left, because the servo motor gets current (high) so that the servo motor moves to the left. Whereas if (read_rotari_kiri $==$ "0") \{digitalWrite (io_rot1, LOW); \} then the servo motor will return to the initial position which is at 0 degrees because it gets current (low) automatically the servo motor will return to the initial position.

$$
\begin{aligned}
& \text { if (read_rotari_kanan == "1") } \\
& \text { \{digitalWrite (io_rot2, HIGH); } \\
& \text { //Serial.print("koplingnyala "); } \\
& \text { if (read_rotari_kanan == "0") } \\
& \text { \{digitalWrite (io_rot2, LOW);\} }
\end{aligned}
$$

Whereas for the right rotary on the canon tank the programming language is if (read_rotari_kanan $==" 1 "$ ) \{digitalWrite (io_rot2, $\mathrm{HIGH}$ ); then the Arduino will order the servo motor to move rotation to the right, because it gets high current so that the servo motor moves to the right. then if Arduino gets the programming language if (read_rotari_kanan $==$ "0") \{digitalWrite (io_rot2, LOW); $\}$ then Arduino commands the servo motor to move to the initial position which is 0 degrees so 
that the direction of rotation on the canon is straight at 0 degrees.

\subsection{Calculation and Selection of Servo Motors on Throttle}

Before carrying out the selection of the driving motor on the Throttle mechanism, a replanning was held to make the Throttle system mechanism that was originally pulled using the alternating connected to the Throttle pedal directly so that the force load borne by the motor is very large, besides that for the motor used it still uses a DC motor that is cannot be mapped, based on the data the mechanism of the thortle system is modified with a servo motor which already has the ability to map to the angle of the motor.

a. Calculates Motor Torque

From measurements using a spring balance on the throtle lever it is known that the force acting on the lever is $15 \mathrm{kgf}$ and is $25 \mathrm{~cm}$ away from the center of the servo motor.

$$
\begin{aligned}
& F=\mathrm{m} \times \mathrm{g} \\
& =15 \mathrm{~kg} \times 9.8 \mathrm{~m} / \mathrm{s}^{\wedge} 2 \\
& =147.15 \mathrm{~kg} \mathrm{~m} / \mathrm{s}^{\wedge} 2 \\
& =147.15 \mathrm{~N}
\end{aligned}
$$

From the above calculation, the required torque is

$$
\begin{aligned}
& T=F X r \\
& =147.15 \mathrm{~N} \times 0.25 \mathrm{~m} \\
& =36.78 \mathrm{Nm} \\
& =36.78 \mathrm{~kg} \mathrm{~m}^{\wedge} 2 / \mathrm{s}^{\wedge} 3
\end{aligned}
$$

So the motor torque needed to drive the throttle system is $36.78 \mathrm{~kg} \mathrm{~m}^{\wedge} 2 / \mathrm{s}^{\wedge} 3$

b. Calculating Motor Power

If it is assumed that motor efficiency is $80 \%$ and Rpm of a servo motor is $15 \mathrm{rpm}$, the motor power used will be:

$$
\begin{aligned}
& \omega=(2 . \pi . n) / 60 \\
& =(2.3,14.15 \mathrm{Rpm}) / 60 \\
& =1.57 \mathrm{Rp} \\
& P=\omega \times \mathrm{T} \\
& =1.57 \mathrm{Rps} \times 36.78 \mathrm{~kg} \mathrm{~m}^{\wedge} 2 / \mathrm{s}^{\wedge} 2
\end{aligned}
$$

$$
\begin{aligned}
& =57.74 \mathrm{~kg} \mathrm{~m}^{\wedge} 2 / \mathrm{s}^{\wedge} 3 \\
& =57.74 \mathrm{Watt}
\end{aligned}
$$

So that with 57.74 Watt power selected RDC7638Ml servo motor.

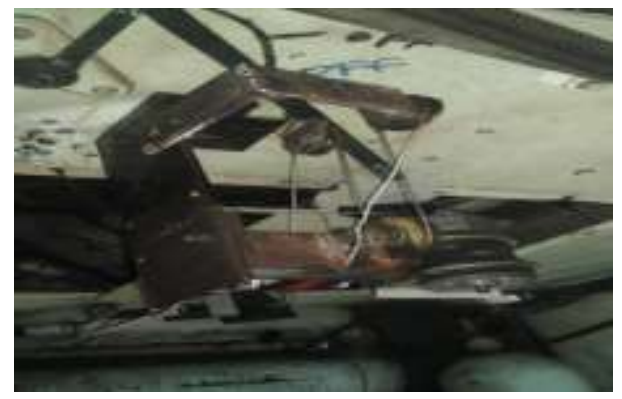

Fig.17 Throttle Driving Mechanism (Source: Selfprocessed)

\subsubsection{Calculate Motor Power of Stop Engine drives}

The results of data collection force that works $20 \mathrm{~N}$ with a lever arm distance to the motor $30 \mathrm{~cm}$. To get the motor power, the following calculation is used then:

$$
\begin{aligned}
\mathrm{T} & =\mathrm{F} \times \mathrm{r} \\
\mathrm{T} & =20 \mathrm{~N} \times 0.3 \mathrm{~m} \\
& =6 \mathrm{Nm}
\end{aligned}
$$

With $6 \mathrm{Nm}$ of torque the 4409MG PDI servo is used having a rotation of $10 \mathrm{Rpm}$ so that the angular velocity can be calculated

$$
\begin{aligned}
\omega & =(2 . \pi . n) / 60 \\
& =2.3,14.10 \mathrm{Rpm} / 60 \\
& =1.05 \mathrm{Rp} \\
\mathrm{P} & =\omega \times \mathrm{T} \\
& =1.05 \mathrm{Rps} \times 36.78 \mathrm{~kg} \mathrm{~m}^{\wedge} 2 / \mathrm{s}^{\wedge} 2 \\
= & 38.5 \mathrm{~kg} \mathrm{~m} \mathrm{~m}^{\wedge} 2 / \mathrm{s}^{\wedge} 3 \\
= & 38.5 \mathrm{Watt}
\end{aligned}
$$

So the motor power needed to drive the engine stop is 38.5 watts using a $4409 M G$ PDI servo motor.

\subsubsection{Calculation and selection of motors on the camera sensor}

Before determining the selection of motors used in the camera sensor drive mechanism as a range finder, data collection is carried out in the form of measuring the weight of the range finder 
and camera mounting sensor mechanism. This is used as a range finder, while the mounting base rotation force is $8 \mathrm{~N}$ with the distance to the servo center of $4 \mathrm{~cm}$, the motor torque can be determined to be able to rotate the camera up and down, namely:

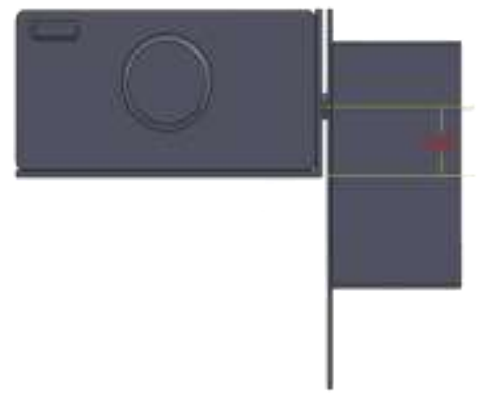

Fig.18 Full Control Mechanisms of dc motor elevation

(Source: Self-processed)

$\mathrm{T}=\mathrm{F} \times \mathrm{r}$

Where:

$\mathrm{T}=$ Torque

$\mathrm{F}=$ Outer force $=5 \mathrm{~N}$

$r=$ arm length $=20 \mathrm{~cm}=0.2 \mathrm{~m}$

So that:

$\mathrm{T}=5 \mathrm{~N} \times 0.2 \mathrm{~m}$

$=1 \mathrm{Nm} \approx 10,2 \mathrm{kgf} . \mathrm{cm}$

So the torque of the motor that drives the camera is $10.2 \mathrm{kgf}$. $\mathrm{Cm}$, while the mounting base motor is:

$$
\begin{aligned}
T & =8 \mathrm{~N} \times 0.4 \mathrm{~m} \\
& =3.2 \mathrm{Nm}
\end{aligned}
$$

From the calculation of the amount of torque for the mounting base is $3.2 \mathrm{Nm}$

For the selection of servo motors that are used based on existing servo motor data the markets are as follows:

\begin{tabular}{|c|c|c|c|c|c|}
\hline Tipe Servo & $\begin{array}{l}\text { Wergint } \\
\text { (gram) }\end{array}$ & $\begin{array}{l}\text { Operating } \\
\text { Voltage(V) }\end{array}$ & $\begin{array}{l}\text { Torque } \\
\text { (N.m) }\end{array}$ & $\begin{array}{l}\text { Current: } \\
\text { (A) }\end{array}$ & $\begin{array}{l}\text { SpeEd } \\
\text { (Rpm) }\end{array}$ \\
\hline PDI-44WGW & 64 & $4-12$ & 7,8 & $0,2-4$ & $\mathrm{~W}$ \\
\hline $\begin{array}{l}\text { ELS- } \\
\text { HV20NG }\end{array}$ & 80 & $5-12$ & 21,5 & $0,5-4$ & 30 \\
\hline ULSBBSIHVV & 78 & $8-12$ & 30,3 & $1-4$ & $\mathbb{Z}$ \\
\hline RL-G/656/I & 是 & 12 & 36 & $1-4$ & 18 \\
\hline
\end{tabular}

Table 1. Types of Servo Motors
So according to the table above used a servo motor with type BLS-HV5209MG which has a specification of the amount of torque produced is $21.5 \mathrm{Nm}$ used as a camera and sensor drive, while to drive the mount base using a servo type RDC7638MI which has a torque of $38 \mathrm{Nm}$, while for the power produced by the motor is:

$$
\begin{aligned}
& \text { Note: } \mathrm{n}=18 \mathrm{rpm} \\
& \begin{aligned}
& \begin{aligned}
\omega & (2 \cdot \pi \cdot \mathrm{n}) / 60 \\
& =
\end{aligned} \\
&=(2 \cdot 3,14 \cdot 18 \mathrm{rpm}) / 60 \\
&=1,884 \mathrm{rps}
\end{aligned}
\end{aligned}
$$

If it is assumed that motor efficiency is $80 \%$, the motor power used will be:

$$
\begin{aligned}
& P=\omega . T \\
& =1,884 \mathrm{rps} .1 \mathrm{~kg} \mathrm{~m}^{\wedge} 2 / \mathrm{s}^{\wedge} 2 \\
& =1,884 \mathrm{~kg} \mathrm{~m}^{\wedge} 2 / \mathrm{s}^{\wedge} 2 \\
& =1,884 \text { watts } \\
& \text { Efficiency }=1.884 /(80 \%)=2.355 \text { watts }
\end{aligned}
$$

So the minimum power of the motor used on the camera servo is 2.355 watts for the holder after $80 \%$ efficiency.

$$
\begin{aligned}
& P=(\omega . T) /(80 \%) \\
& =1,884 \text { rps. } 3.2 \mathrm{~kg} \mathrm{~m}^{\wedge} 2 / \mathrm{s}^{\wedge} 2 \\
& =7,538 \text { watts }
\end{aligned}
$$

literature review relating to certain definitions.

\section{CONCLUSIONS}

From the calculations that have been done to modify the mechanism of the Throttle system, 
engine stop, and input data on the elevation system, and the rotary, some conclusions can be drawn, namely:

a. Modify the Throttle mechanism using a servo motor actuator so that the Throttle System is easier to carry out maping on the servo motor, so makes it easier for Throttle to be more precise. The motor used with the type RD-C7638MI with a power of 57.74 watts.

b. Engine Stop system is more responsive and accurate after carrying out modification of the drive on the tool by using a PDI 4409MG servo motor with 38.5 watts of power

\section{REFERENCES}

Awadallah, M. A. 2006. Automatic Diagnosis and Location of Open-Switch. IEEE TRANSACTIONS ON ENERGY CONVERSION ,, 104-111.

Deni. 2018. Elevation and rotation. surabaya: Sttal.

Harianto, I. 2008. Digital signal processing. Surabaya: Surabaya.

http://jendeladenngabei.blogspot.com/2012/11/dcchopper-tipe-buck-buck-converter.html

https://teknikelektronika.com/ understanding-relayfungsi-relay/
C. Rotary drive input system and canon tank AMX 10 PAC 90 dome elevation can be provided through the camera sensor input so that it can carry out target ploting then the elevation and rotation of the dome follow servo degrees based on the camera sensor.

It is hoped that the researchers can further refine the elevation and rotary angle data input systems more precisely and accurately with further range in detecting targets using a range finder sensor that uses a laser. So that making the design of this mechanism into a breakthrough in the world of education, especially in the STTAL environment, and can be developed to be more perfect.

Piscataway. 2000, may week. The Authoritative Dictionary of IEEE Standards Terms. p. 7381-2601.

Rifai, E. Y. 2015, August 21. Action Camera. Retrieved from Jalan Tikus: https://jalantikus.com/gadgets/tips-beliaction-camera-gopro/

Rusmandi, f. 2006. metal science. metal science, 32-40.

Sanitary. 2009. relay application. Bali: Bali.

Serway, R. A. 2003. 6th Ed. Brooks Cole. Physics for Scientists and Engineers, 32-45.

sujadi. 2005. Arduino application theory. Yogyakarta: 2005. 